\title{
Hydrogen sulfide reduced renal tissue fibrosis by regulating autophagy in diabetic rats
}

\author{
LIN LI $^{1}$, TING XIAO ${ }^{1}$, FANG LI $^{1}$, YAN LI ${ }^{1}$, OU ZENG ${ }^{1}$, MAOJUN LIU $^{1}$, \\ BIAO LIANG ${ }^{1}$, ZINING LI ${ }^{1}, \mathrm{CHUN} \mathrm{CHU}^{2}$ and JUN YANG ${ }^{1}$ \\ ${ }^{1}$ Department of Cardiology, The First Affiliated Hospital of South China University; ${ }^{2}$ Department of Pharmacy, \\ The Second Affiliated Hospital of South China University, Hengyang, Hunan 421001, P.R. China
}

Received February 28, 2016; Accepted March 9, 2017

DOI: $10.3892 / \mathrm{mmr} .2017 .6813$

\begin{abstract}
The present study aimed to explore the effect of hydrogen sulfide $\left(\mathrm{H}_{2} \mathrm{~S}\right)$ on renal tissue fibrosis and its mechanism in diabetic rats. Rats were randomly divided into four groups (n=13/group): Control group; induced diabetes mellitus group (STZ); induced diabetes mellitus treated with $\mathrm{H}_{2} \mathrm{~S}$ group ( $\mathrm{STZ}+\mathrm{H}_{2} \mathrm{~S}$ ); normal rats treated with $\mathrm{H}_{2} \mathrm{~S}$ group $\left(\mathrm{H}_{2} \mathrm{~S}\right)$. The diabetic model was induced by intraperitoneal (i.p.) injections of $40 \mathrm{mg} / \mathrm{kg}$ body weight streptozotocin (STZ); the control group was treated with saline every day (i.p); NaHS (100 $\mu \mathrm{mol} / \mathrm{kg}$ i.p.) was administered to rats of STZ $+\mathrm{H}_{2} \mathrm{~S}$ group and $\mathrm{H}_{2} \mathrm{~S}$ group. After 8 weeks, rat body weight and $24 \mathrm{~h}$ proteinuria levels were determined in each group, renal pathological morphology was analyzed by Masson's trichrome staining, collagen IV content was detected by immunohistochemistry, and periodic acid-Schiff (PAS) staining was performed on renal glomerular and tubular basement membranes. The expression levels of matrix metalloproteinase 9 (MMP9), MMP7, tissue inhibitor of metalloproteinase 1 (TIMP1), superoxide dismutase (SOD), serine/threonine kinase AKT, transforming growth factor (TGF)- $\beta 1$, nuclear factor $(\mathrm{NF})-\kappa \mathrm{B}$ and several autophagy related proteins were assessed by western blot analysis. Compared with the control group, renal tissue fibrosis was observed, collagen IV expression and the $24 \mathrm{~h}$ proteinuria quantity was markedly increased
\end{abstract}

Correspondence to: Professor Jun Yang, Department of Cardiology, The First Affiliated Hospital of South China University, 68 Chuanshan Road, Hengyang, Hunan 421001, P.R. China E-mail: yangjunincn@163.com

Abbreviations: DN, diabetic nephropathy; $\mathrm{H}_{2} \mathrm{~S}$, hydrogen sulfide; NaHS, sodium hydrosulfide; ECM, extracellular matrix; MMP, matrix metalloproteinases; TIMP, tissue inhibitor of metalloproteinases; CBS, cystathionine $\beta$ synthase; SOD, superoxide dismutase; AKT, AKT serine/threonine kinase; TGF- $\beta 1$, transforming growth factor- $\beta 1$; $\mathrm{NF}-\kappa \mathrm{B}$, nuclear factor- $\kappa \mathrm{B}$

Key words: diabetic nephropathy, hydrogen sulfide, autophagy, superoxide dismutase, AKT serine/threonine kinase, transforming growth factor- $\beta 1$, nuclear factor- $\kappa \mathrm{B}$ and the amount of PAS positive material in renal glomerular and tubular basement membranes was notably increased in STZ-treated rats. Furthermore, the expression levels of MMP9, MMP7, TIMP1, autophagy-associated proteins, AKT, TGF- $\beta 1$ and NF- $\kappa$ B protein were significantly increased, and SOD expression levels were significantly decreased in the STZ group compared with the control $(\mathrm{P}<0.05)$. In the $\mathrm{H}_{2} \mathrm{~S}+\mathrm{STZ}$ group, renal tissue fibrosis and the expression of collagen IV were improved, $24 \mathrm{~h}$ proteinuria was decreased, the amount of PAS positive material in renal glomerular and tubular basement membranes was decreased, the expression levels MMP9, MMP7, TIMP1, autophagy-associated proteins, AKT, TGF- $\beta 1$ and $N F-\kappa B$ protein were significantly decreased, and the expression levels of SOD were significantly increased compared with the STZ group $(\mathrm{P}<0.05)$. In conclusion, $\mathrm{H}_{2} \mathrm{~S}$ may improve renal tissue fibrosis by inhibiting autophagy, upregulating SOD and downregulating AKT, TGF- $\beta 1$ and $\mathrm{NF}-\kappa \mathrm{B}$.

\section{Introduction}

Diabetic nephropathy (DN) is a leading cause of end-stage renal disease (ESRD). The worldwide occurrence of DN is increasing, and this disease is associated with increased morbidity and mortality in patients with type 1 and type 2 diabetes (1). DN is characterized by the accumulation of extracellular matrix (ECM), resulting in progressive kidney fibrosis that leads to kidney function decline and irreversible loss of tissue (2). The increasing prevalence of DN has resulted in a growing research focus on this disease. Therefore, the identification of a novel therapeutic target in the management of DN is required.

Autophagy is emerging as a key cellular stress response that is involved in a variety of disease states, including DN (3). Autophagy is a highly conserved 'self-feeding' pathway involved in degrading and recycling macromolecules and damaged organelles, to maintain intracellular homeostasis (4). This cellular function serves important roles in human health and disease. Generally, autophagy serves a dual purpose; it may perform a cytoprotective or deleterious role in the body, depending on the type and severity of the inducing injury (5). A certain degree of autophagic activity serves a critical role in promoting tissue homeostasis and cell survival. However, 
excessive autophagic activity may also contribute to type II programmed cell death and, in certain circumstances, promote the development of DN (6).

Hydrogen sulfide $\left(\mathrm{H}_{2} \mathrm{~S}\right)$ is an endogenously produced gaseous molecule with important roles in cellular signaling. This chemical has been implicated in the regulation of inflammatory responses, cardiovascular functions, renal functioning and the gastrointestinal system. Furthermore, $\mathrm{H}_{2} \mathrm{~S}$ has been shown to exert potent cytoprotective abilities against tissue injury, including organ fibroses such as myocardial and renal fibrosis (7). However, the role of $\mathrm{H}_{2} \mathrm{~S}$ and autophagy in the pathogenesis of DN, and the relationship between $\mathrm{H}_{2} \mathrm{~S}$ and the dysregulation of autophagy remains unclear. Therefore, further studies are required to clarify these mechanisms in detail. The present study established a streptozotocin (STZ)-induced diabetic rat model to investigate the role of $\mathrm{H}_{2} \mathrm{~S}$ and autophagy in the pathogenesis of DN, and the protective effects of $\mathrm{H}_{2} \mathrm{~S}$ against DN.

\section{Materials and methods}

Animals and reagents. Adult male Sprague-Dawley rats $(\mathrm{n}=52$; weight, $280 \pm 40 \mathrm{~g}$ ) were obtained from the animal experiment center of South China University (Henyang, China). The study was approved by the Ethics Committee of the Department of Laboratory Animals of South China University [animal qualified number: SYXK (Hunan), 2015-0006]. All rats were maintained in a climate-controlled room with a 12-h light/dark cycle, at constant temperature $\left(23 \pm 1^{\circ} \mathrm{C}\right)$ and humidity $(40-50 \%)$ with free access to food and water. Antibodies against collagen IV (cat. no. BA3585-2), GAPDH (cat. no. PB0141), matrix metalloproteinase 9 (MMP9; cat. no. BA0573), MMP7 (cat. no. BA2110), tissue inhibitor of metalloproteinase 1 (TIMP1; cat. no. BA3727), superoxide dismutase (SOD; cat. no. BA3836-2), AKT (cat. no. BA0631), transforming growth factor (TGF)- $\beta 1$ (cat. no. BA0290) and nuclear factor (NF) $-\kappa B$ (cat. no. BA1872-2) were purchased from Wuhan Boster Biological Technology, Ltd. (Wuhan, China). Antibodies against microtubule associated protein light chain 3 (LC3; cat. no. 12741), autophagy related (Atg)-3 (cat. no. 3415), Atg5 (cat. no. 12994), Atg7 (cat. no. 8558), Atg12 (cat. no. 4180) and Atg16 (cat. no. 8089) were purchased from Cell Signaling Technology, Inc. (Danvers, MA, USA). The antibody against cystathionine $\beta$ synthase (CBS; cat. no. RS-4193R) was obtained from Shanghai Ruiqi Biological Technology Co., Ltd. The goat anti-rabbit horseradish peroxidase-conjugated IgG secondary antibody (cat. no. 074-1506) was purchased from SeraCare Life Sciences (Milford, MA, USA). Sodium hydrogen sulfide (NaHS), an exogenous donor of $\mathrm{H}_{2} \mathrm{~S}$, was purchased from Sigma-Aldrich (Merck KGaA, Darmstadt, Germany). The bicinchoninic acid (BCA) protein quantitative kit and the cell lysis solution were purchased from Beyotime Institute of Biotechnology (Guangzhou, China).

Animal model and grouping. All rats had free access to food and water and, following 7 days of acclimatization, the rats were randomly divided into four equal groups ( $\mathrm{n}=13 /$ group): Control group, STZ group, $\mathrm{STZ}+\mathrm{H}_{2} \mathrm{~S}$ group and $\mathrm{H}_{2} \mathrm{~S}$ group. The $\mathrm{STZ}$ and $\mathrm{STZ}+\mathrm{H}_{2} \mathrm{~S}$ groups received intraperitoneal injections of $40 \mathrm{mg} / \mathrm{kg}$ body weight STZ, 5\% glucose water was provided for STZ-treated rats within $24 \mathrm{~h}$ to prevent hypoglycemic shock, and blood sugar levels were tested $72 \mathrm{~h}$ after injection. The diabetic animal model was considered successful if blood glucose levels rose to $>16.7 \mathrm{mmol} / \mathrm{l}^{-1}$. Following animal model set-up, the $\mathrm{H}_{2} \mathrm{~S}$ and $\mathrm{STZ}+\mathrm{H}_{2} \mathrm{~S}$ groups were intraperitoneally administered the $\mathrm{H}_{2} \mathrm{~S}$ donor NaHS after the models were established successfully, at a dose of $100 \mu \mathrm{mol} / \mathrm{kg} /$ day for a further 8 weeks. The first dose of NaHS was administered $24 \mathrm{~h}$ after models were successfully established. Control and STZ groups were treated with an equivalent volume of intraperitoneal $0.9 \%$ saline for 8 weeks. During this 8 -week period a total of 12 rats died (control, $\mathrm{n}=2 ; \mathrm{STZ}, \mathrm{n}=4 ; \mathrm{STZ}+\mathrm{H}_{2} \mathrm{~S}, \mathrm{n}=3 ; \mathrm{H}_{2} \mathrm{~S}, \mathrm{n}=3$ ); the overall survival rate was $77 \%$. Diabetic rats were observed to be unresponsive and lackluster, and displayed various degrees of polydipsia, polyphagia, diuresis and moved slowly.

Specimen collection and processing. At the end of the 8 weeks, the $24 \mathrm{~h}$ proteinuria levels were determined by using a UP ELISA kit (cat. no. SBJ-H1384; Nanjing Senbeijia Biological Technology Co., Ltd. Nanjing, China), and the rats were sacrificed following chloral hydrate anesthesia. Both kidneys were removed; the right kidney was immersed in $10 \%$ formalin and embedded in paraffin. The left kidney was frozen $\left(-70^{\circ} \mathrm{C}\right)$ and later used for western blot analysis.

Histopathological examinations. Paraffin-embedded specimens were cut into $5 \mu \mathrm{m}$ thick sections and stained with Masson's trichrome. Five random microscopic fields per well were quantified at a magnification of $\mathrm{x} 400$ using a $\mathrm{BH}-2$ light microscope (Olympus Corporation, Tokyo, Japan).

Immunohistochemistry. Paraffin-embedded specimens were cut into $4 \mu \mathrm{m}$ thick sections, dewaxed, rehydrated and boiled. Sections were washed three times for $5 \mathrm{~min}$ each in PBST [PBS (pH 7.4), 0.05\% Tween-20], blocked with 5\% bovine serum albumin (Wuhan Boster Biological Technology, Ltd.) for $10 \mathrm{~min}$ at room temperature and then incubated with the collagen IV primary antibody (diluted 1:50) overnight at $4^{\circ} \mathrm{C}$. The following day, sections were washed three times for $5 \mathrm{~min}$ each in PBST, incubated with horseradish peroxidase-conjugated secondary antibodies $(1: 2,000)$ for $30 \mathrm{~min}$ at $37^{\circ} \mathrm{C}$, washed in PBST and visualized using a DAB staining kit (Nanjing Senbeijia Biological Technology Co., Ltd.). Sections were counterstained with hematoxylin and collagen IV deposition was observed at a magnification of x400 using a digital microscope (Olympus Corporation).

Periodic acid-Schiff (PAS) staining. Paraffin-embedded kidney specimens were cut into $2-3 \mu \mathrm{m}$ thick sections, dewaxed, rehydrated, and oxidized with $5 \%$ periodate for 6-8 $\mathrm{min}$ at $15^{\circ} \mathrm{C}$. Sections were subsequently washed with distilled water for $2 \mathrm{~min}$, placed into colorless Schiff's reagent and incubated in the dark for $20 \mathrm{~min}$ at $15^{\circ} \mathrm{C}$. The samples were then droplet washed twice for $1 \mathrm{~min}$ with sodium sulfite solution $(0.5 \%)$, rinsed with running water for $2 \mathrm{~min}$, counterstained with hematoxylin for $1 \mathrm{~min}$ at $18^{\circ} \mathrm{C}$, washed in running water and differentiated with $1 \%$ hydrochloric acid alcohol at $18^{\circ} \mathrm{C}$. Samples were then repeatedly rinsed with running water, the blue stain was developed with warm water and sections were dehydrated with graded ethanol and sealed with 
neutral balsam, and the PAS-positive material was observed in the renal glomerular and tubular basement membranes under high-power magnification (x400) using a BH-2 light microscope.

Western blot analysis. Proteins were extracted in ice-cold radioimmunoprecipitation assay buffer containing a protease inhibitor cocktail (100X; Beyotime Institute of Biotechnology), and quantified using the BCA colorimetric method. Proteins (50 $\mu \mathrm{g} /$ lane) were separated by $10 \%$ SDS-PAGE and transferred to polyvinylidene difluoride membranes. Membranes were blocked with 5\% skimmed milk powder in TBST buffer $[10 \mathrm{mM}$ Tris $(\mathrm{pH} 7.5)$, $150 \mathrm{mM} \mathrm{NaCl}, 0.05 \%$ Tween-20] for $2 \mathrm{~h}$ and incubated with anti-MMP9, anti-MMP7, anti-TIMP1, anti-SOD, anti-AKT, anti-TGF- 31 , anti-NF- $\mathrm{B}$ (all 1:400) and anti-LC3, anti-Atg3, anti-Atg5, anti-Atg7, anti-Atg12, anti-Atg16 (all 1:1,000) antibodies for $1 \mathrm{~h}$ at $37^{\circ} \mathrm{C}$, and then overnight at $4^{\circ} \mathrm{C}$. GAPDH served as the endogenous control. The membranes were washed three times for $10 \mathrm{~min}$ each and then incubated with horseradish peroxidase-conjugated secondary antibodies $(1: 2,000)$ for $2 \mathrm{~h}$ at room temperature. The membranes were detected using Western Blotting Luminol reagent (Santa Cruz Biotechnology, Inc., Dallas, TX, USA), protein bands were visualized using the FluorChem ${ }^{\circledR}$ FC2 Imaging System (ProteinSimple; Bio-Techne, Minneapolis, MN, USA) and the band density was semi-quantified using AlphaView v3.2.2 software (ProteinSimple; Bio-Techne).

Statistical analysis. Data were analyzed using SPSS v18.0 software (SPSS, Inc., Chicago, IL, USA), and expressed as the mean \pm standard deviation of the mean. Comparisons between groups were performed using one-way analysis of variance followed by Fisher's least significant difference test. $\mathrm{P}<0.05$ was considered to indicate a statistically significant difference.

\section{Results}

Changes in proteinuria. The $24 \mathrm{~h}$ proteinuria was significantly increased in the STZ group $(\mathrm{P}<0.05)$, compared with the untreated control group. Notably, the $24 \mathrm{~h}$ proteinuria level was significantly decreased in the $\mathrm{STZ}+\mathrm{H}_{2} \mathrm{~S}$ group, following $\mathrm{H}_{2} \mathrm{~S}$ intervention $(\mathrm{P}<0.05$; Table I).

Pathological morphology. Masson's trichrome staining was performed to observe collagen deposition; blue staining indicated the presence of collagen in the tissues. There were no collagen fibers distinctly observed in the renal interstitial areas of the control group, however the glomerular and tubular basement membranes were lightly stained. In the STZ treatment group collagen fibers were present in the renal interstitium, combined with heavy staining of the glomerular and tubular basement membranes. Notably, compared with the STZ group, collagen fiber staining was markedly reduced in the renal interstitial areas of STZ $+\mathrm{H}_{2} \mathrm{~S}$ rats, and the glomerular and tubular basement membranes were also stained lighter in these rats. The $\mathrm{H}_{2} \mathrm{~S}$ group renal interstitium did not appear to display collagen staining, with light staining present only on the glomerular and tubular basement membranes (Fig. 1).
Table I. The $24 \mathrm{~h}$ proteinuria in STZ-diabetic rats.

Group

$24 \mathrm{~h}$ proteinuria $(\mathrm{mg} / 24 \mathrm{~h})$

$\begin{array}{ll}\text { Control } & 11.8 \pm 3.3 \\ \text { STZ } & 44.5 \pm 6.4^{\mathrm{a}} \\ \mathrm{STZ}+\mathrm{H}_{2} \mathrm{~S} & 26.6 \pm 6.1^{\mathrm{b}} \\ \mathrm{H}_{2} \mathrm{~S} & 12.6 \pm 4.0\end{array}$

Values are expressed as the mean \pm standard deviation. ${ }^{\mathrm{a}} \mathrm{P}<0.05$ vs. control group, ${ }^{b} \mathrm{P}<0.05$ vs. STZ group. STZ, streptozotocin; $\mathrm{H}_{2} \mathrm{~S}$, hydrogen sulfide.

Immunohistochemistry. Immunohistochemical analysis was performed to observe collagen IV deposition and brown staining indicated the presence of collagen IV in the tissues. In the control group, collagen IV was lightly observed in the glomerulus, tubules and interstitial areas. In the STZ group, collagen IV positivity was observed in the glomerulus, tubules and interstitial areas. However, in the STZ $+\mathrm{H}_{2} \mathrm{~S}$ group, collagen IV positive staining was decreased in these areas, compared with the STZ group. In the $\mathrm{H}_{2} \mathrm{~S}$ group, collagen IV was not observed in the renal tubules, the glomerulus or the renal interstitium (Fig. 2).

PAS staining. Fuchsia staining represented PAS positive material. PAS staining was lowest in the renal glomerular and tubular basement membranes of the control group. Marked PAS staining of the renal glomerular and tubular basement membranes was observed in the STZ group. Compared with the STZ group, the presence of PAS positive material in renal glomerular and tubular basement membranes was markedly improved in the $\mathrm{STZ}+\mathrm{H}_{2} \mathrm{~S}$ group. PAS positive staining of the renal glomerular and tubular basement membranes was low in the $\mathrm{H}_{2} \mathrm{~S}$ group (Fig. 3).

Effects of $S T Z$ and $\mathrm{H}_{2} \mathrm{~S}$ on $C B S$ protein expression. CBS is an enzyme that can endogenously produce $\mathrm{H}_{2} \mathrm{~S}$ in kidney tissue. The present study observed that CBS expression was significantly decreased in the STZ group $(\mathrm{P}<0.05)$. Compared with the STZ group, however, the expression levels of CBS protein were significantly increased in the $\mathrm{STZ}+\mathrm{H}_{2} \mathrm{~S}$ group $(\mathrm{P}<0.05$; Fig. 4). These results indicated that renal fibrosis was elevated following STZ treatment, and was markedly improved with $\mathrm{H}_{2} \mathrm{~S}$ treatment; $\mathrm{H}_{2} \mathrm{~S}$ may therefore improve renal tissue fibrosis.

Effects of STZ and $\mathrm{H}_{2} \mathrm{~S}$ on MMP9, MMP7, TIMP1 and SOD expression. The expression of MMP9, MMP7 and TIMP1 protein were significantly increased in the STZ group compared with the control group $(\mathrm{P}<0.05)$, whereas SOD protein was significantly decreased in this group $(\mathrm{P}<0.05)$. However, the expression of MMP9, MMP7 and TIMP1 protein were significantly decreased and SOD protein was significantly increased in the $\mathrm{STZ}+\mathrm{H}_{2} \mathrm{~S}$ group, compared with the STZ group $(\mathrm{P}<0.05)$. There was no difference in MMP9, MMP7, TIMP1 and SOD protein expression between the control and $\mathrm{H}_{2} \mathrm{~S}$-only groups (Fig. 5). 


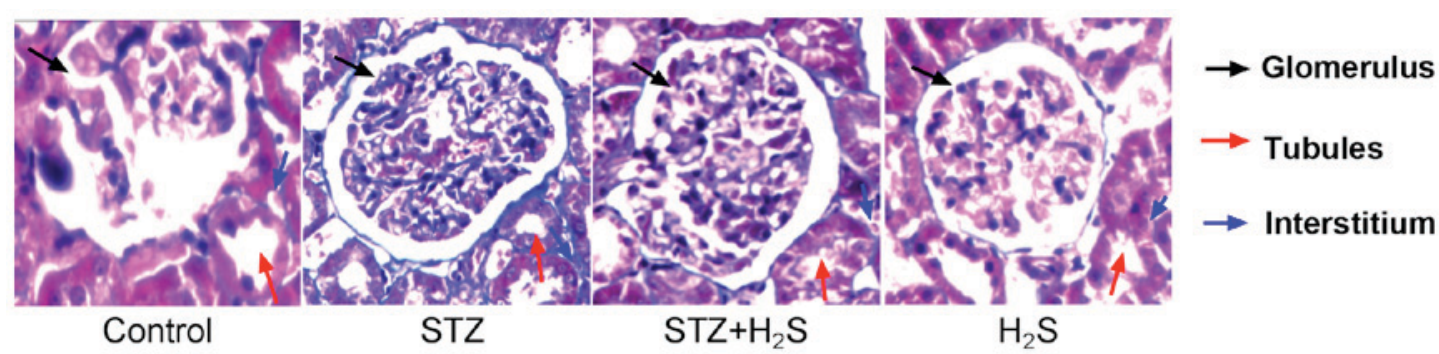

Figure 1. Masson's trichrome staining in STZ-diabetic rats. Pathologic morphology and collagen deposition was assessed using Masson's trichrome staining. Magnification, $\mathrm{x} 400$. STZ, streptozotocin; $\mathrm{H}_{2} \mathrm{~S}$, hydrogen sulfide.

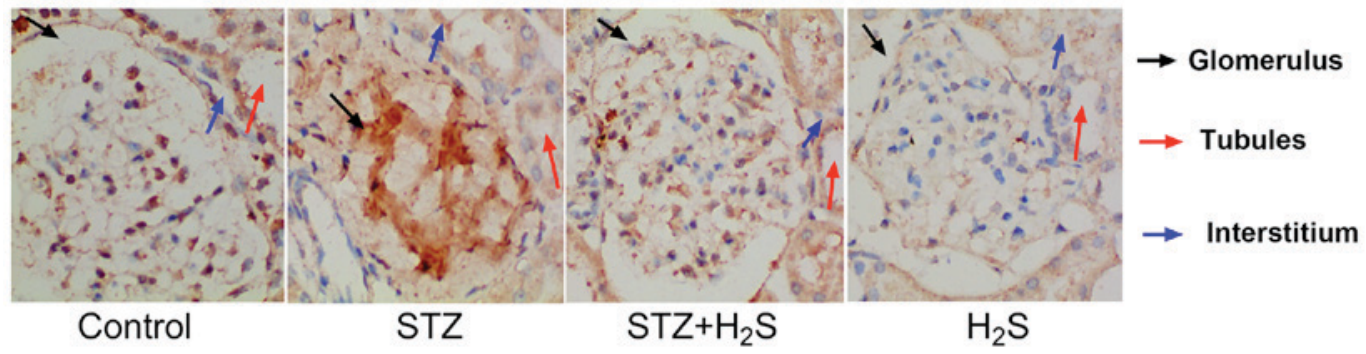

Figure 2. Immunohistochemical analysis of collagen IV in STZ-diabetic rats. Kidney tissues were stained for collagen IV and counterstained with hematoxylin. Magnification, x400. STZ, streptozotocin; $\mathrm{H}_{2} \mathrm{~S}$, hydrogen sulfide.

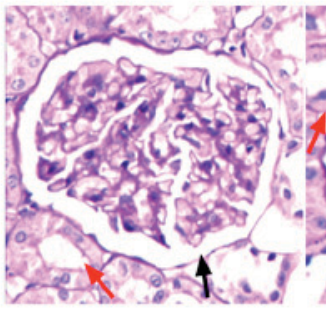

Control

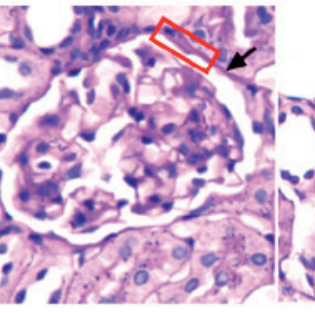

STZ

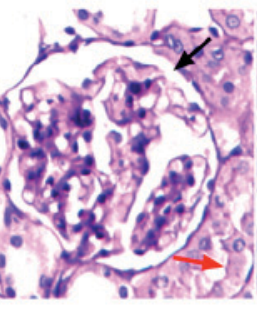

$\mathrm{STZ}+\mathrm{H}_{2} \mathrm{~S}$

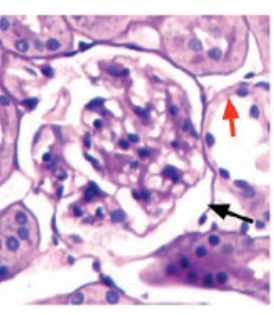

$\mathrm{H}_{2} \mathrm{~S}$ $\rightarrow \begin{aligned} & \text { Glomerular basement } \\ & \text { membranes }\end{aligned}$

$\rightarrow$ Tubular basement

membranes

Fuschia

Figure 3. Periodic acid-Schiff staining in renal tissue from STZ-diabetic rats. Magnification, $\mathrm{x} 400$. STZ, streptozotocin; $\mathrm{H}_{2} \mathrm{~S}$, hydrogen sulfide.

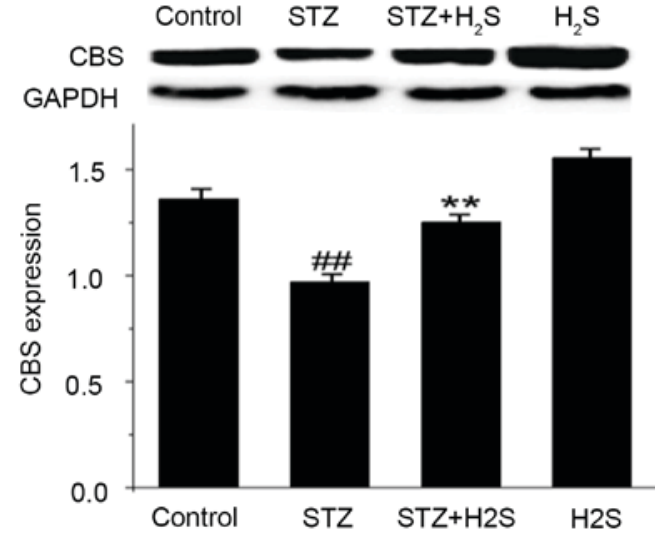

Figure 4. Expression of renal CBS in STZ-diabetic rats. CBS levels were assessed by western blot analysis. Data are presented as the mean \pm standard deviation ( $\mathrm{n}=3) .{ }^{\# /} \mathrm{P}<0.05$ vs. the control group, ${ }^{* *} \mathrm{P}<0.05$ vs. the STZ group. STZ, streptozotocin; $\mathrm{H}_{2} \mathrm{~S}$, hydrogen sulfide; CBS, cystathionine $\beta$ synthase.

Effects of STZ and $\mathrm{H}_{2} \mathrm{~S}$ on LC3, Atg3, Atg5, Atg7, Atg12 and Atg16 expression. The expression of LC3, Atg3, Atg5, Atg7,
Atg12 and Atg16 was significantly increased in the STZ group, compared with the control group $(\mathrm{P}<0.05)$. However, the expression levels of these proteins were significantly decreased in the STZ $+\mathrm{H}_{2} \mathrm{~S}$ group, compared with the STZ group $(\mathrm{P}<0.05)$. There was no difference in LC3, Atg3, Atg5, Atg7, Atg12 or Atg16 protein expression between the control group and the $\mathrm{H}_{2} \mathrm{~S}$-only group (Fig. 6).

Effects of STZ and $\mathrm{H}_{2} \mathrm{~S}$ on TGF- $\beta 1, N F-\kappa B$ and $A K T$ expression. The expression levels of TGF- $\beta 1, \mathrm{NF}-\kappa \mathrm{B}$ and AKT were significantly increased in the STZ group compared with the control group $(\mathrm{P}<0.05)$. The expression levels of TGF- $\beta 1$, NF- $\mathrm{KB}$ and AKT were significantly decreased in the STZ + $\mathrm{H}_{2} \mathrm{~S}$ group, compared with the $\mathrm{STZ}$ group $(\mathrm{P}<0.05)$. There was no difference in TGF- $\beta 1, \mathrm{NF}-\kappa \mathrm{B}$ or AKT expression between the control group and the $\mathrm{H}_{2} \mathrm{~S}$ group (Fig. 7).

\section{Discussion}

The results of the present study demonstrated a significant increase in urinary protein content in diabetic rats. 

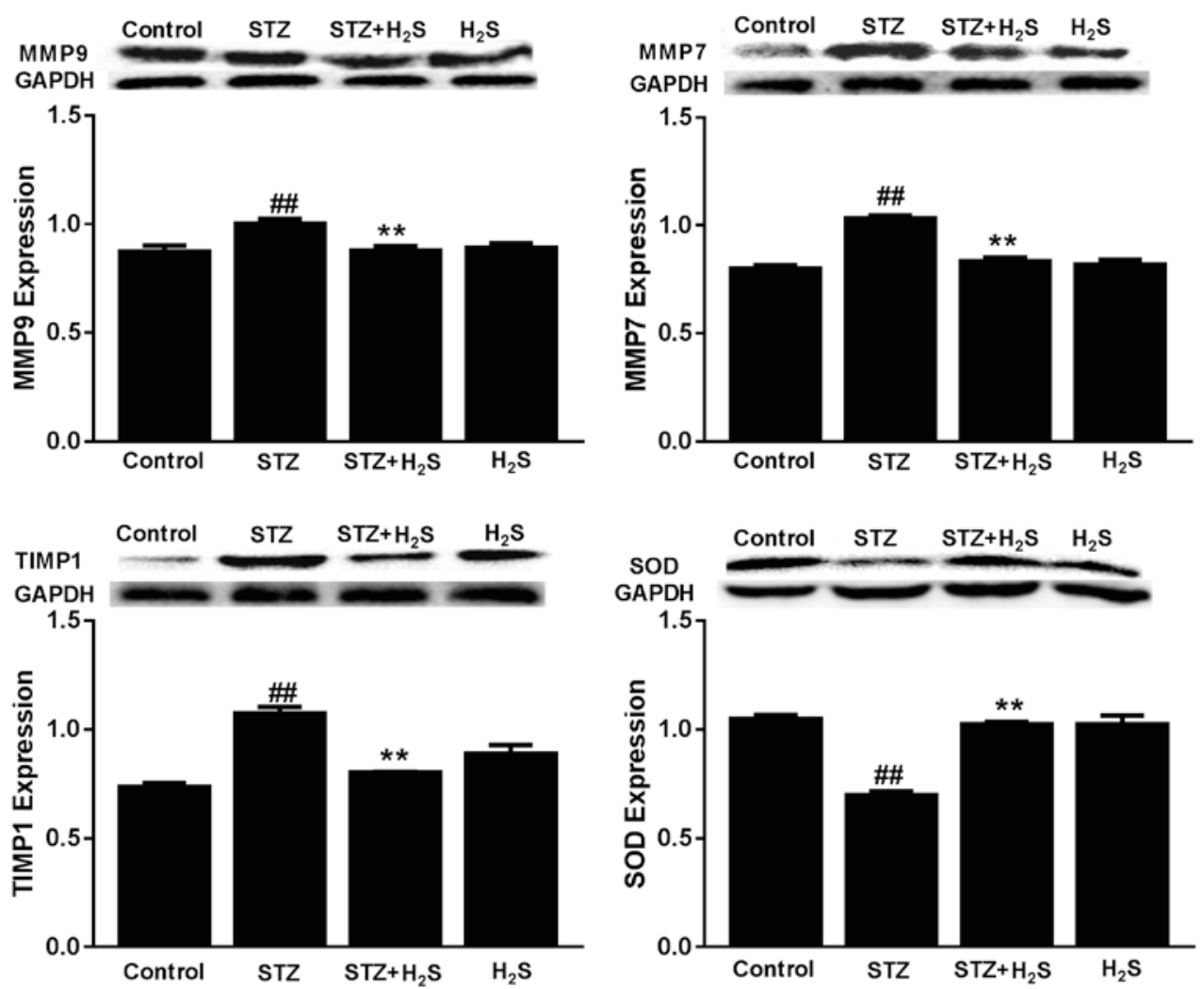

Figure 5. Expression of MMP9, MMP7, TIMP1 and SOD in STZ-diabetic rats. Data are presented as the mean \pm standard deviation ( $\mathrm{n}=3$ ). ${ }^{\# / P}<0.05$ vs. the control group, ${ }^{* *} \mathrm{P}<0.05$ vs. the STZ group. MMP, matrix metalloproteinase; TIMP1, tissue inhibitor of metalloproteinase; SOD, superoxide dismutase; STZ, streptozotocin; $\mathrm{H}_{2} \mathrm{~S}$, hydrogen sulfide.
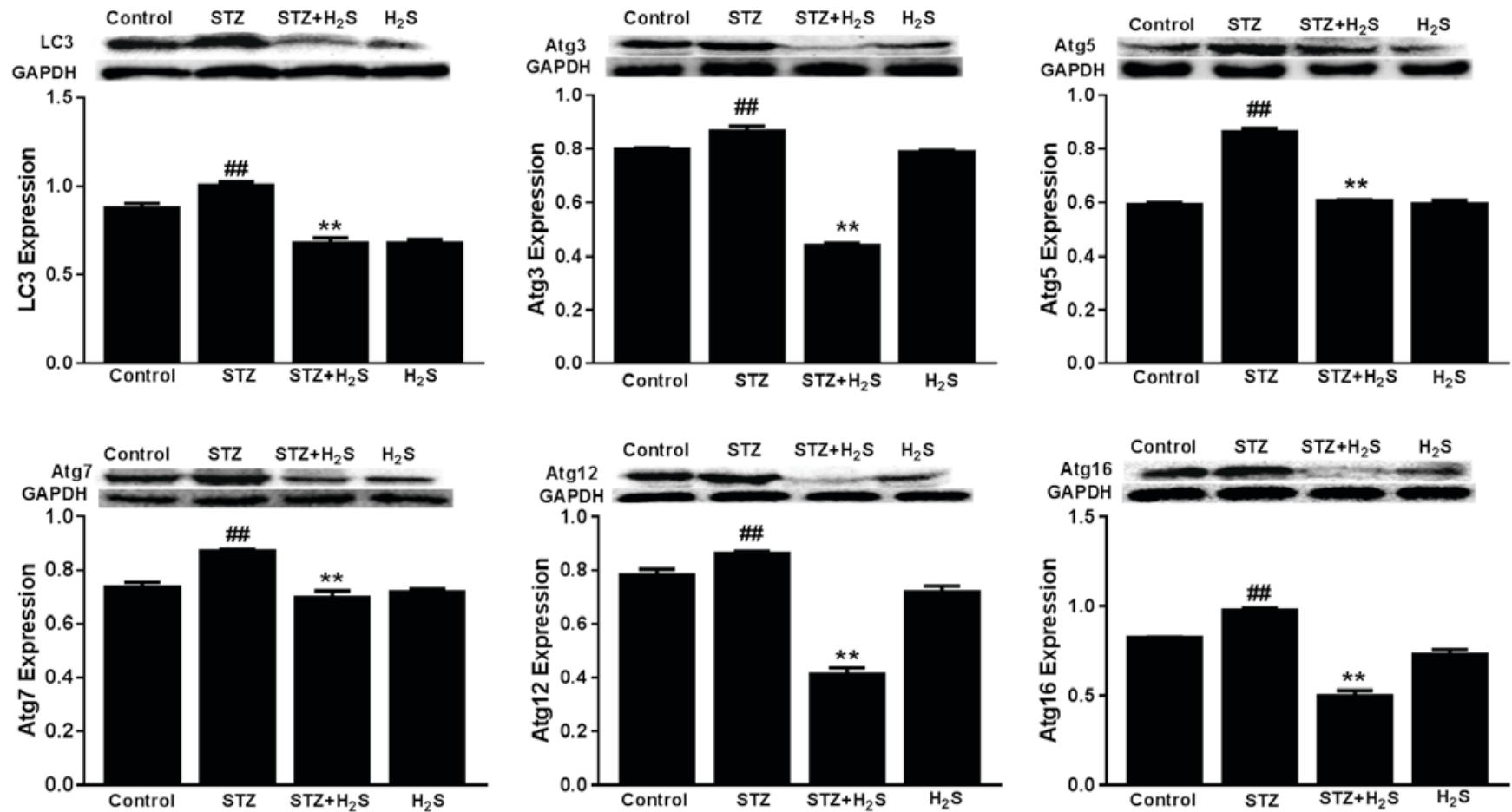

Figure 6. Expression of LC3, Atg3, Atg5, Atg7, Atg12 and Atg16 in STZ-diabetic rats. Data are presented as the mean \pm standard deviation (n=3). ${ }^{\# / P}<0.05$ vs. the control group, ${ }^{* *} \mathrm{P}<0.05$ vs. the STZ group. LC3, microtubule associated protein light chain 3; Atg, autophagy related; STZ, streptozotocin; $\mathrm{H}_{2} \mathrm{~S}$, hydrogen sulfide.

Immunohistochemical examination discovered prominent renal tissue fibrosis and significant upregulation of renal tissue collagen IV expression amongst STZ-induced diabetic rats. The results of Masson's staining indicated that collagen fibers 

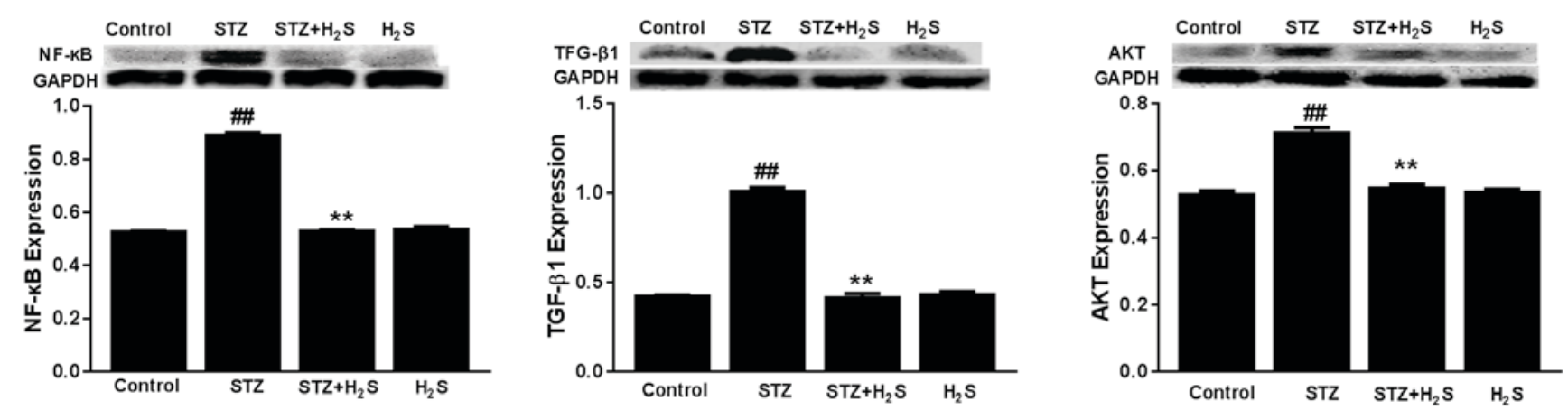

Figure 7. Expression of TGF- $\beta 1, \mathrm{NF}-\kappa \mathrm{B}, \mathrm{AKT}$ protein in $\mathrm{STZ}$-diabetic rats. Data are presented as the mean \pm standard deviation ( $\mathrm{n}=3$ ). ${ }^{\# \#} \mathrm{P}<0.05 \mathrm{vs}$. the control group, ${ }^{* *} \mathrm{P}<0.05$ vs. the $\mathrm{STZ}$ group. TGF- $\beta 1$, transforming growth factor $\beta 1 ; \mathrm{NF}-\kappa \mathrm{B}$, nuclear factor- $\kappa \mathrm{B}$; $\mathrm{STZ}$, streptozotocin; $\mathrm{H}_{2} \mathrm{~S}$, hydrogen sulfide.

were present in the renal interstitium in the STZ group and the presence of PAS-positive material in renal glomerular and tubular basement membranes was markedly increased in the STZ group compared with the control group. These results also indicated that there was dysregulation of MMPs and TIMP expression in the renal tissue of diabetic rats. Collectively, these results suggested the presence of renal tissue fibrosis in diabetic rats. Furthermore, the present study observed an elevation of activated autophagy biomarkers, including LC3, Atg3, Atg5, Atg7, Atg12 and Atg16. These biomarkers were upregulated in the renal tissue of diabetic rats, suggesting that autophagic activation may be associated with renal tissue fibrosis in these rats. Previous research has indicated that renal fibrosis is accompanied by an upregulation of autophagy (6), whereas a different study suggested that a downregulation of autophagy occurs in diabetic nephropathy (8). Such a difference may be associated with disease duration and stage of diabetic nephropathy; the majority of the autophagic downregulation is observed in early stages of diabetes and is associated with diabetic kidney hypertrophy, whereas enhanced autophagy is often observed in the late stages of diabetes and is associated with diabetic kidney fibrosis (8). Evidence of cellular autophagy inhibition was observed in the proximal and distal tubules of early STZ-induced diabetic rats by electron microscopy analysis, three days following STZ administration (8). Whereas some studies have demonstrated the presence of autophagy in renal tissue fibrosis $(9,10)$. Therefore, it is speculated that the level of autophagy may be upregulated when significant renal tissue fibrosis occurs in DN. This phenomenon was also observed in another experimental report (11). Such time-dependent alterations also conform to the characteristics of autophagy: Early mild damage leads to protective autophagy, whereas sustained serious damage may result in traumatic autophagy. However, whether protective autophagy or traumatic autophagy occurred in the present study remains unclear.

Excessive oxidative stress and autophagy has previously been demonstrated in DN. Reactive oxygen species (ROS) are mediators of autophagic activation, furthermore, ROS-induced activation of autophagy may result in alternative outcomes that promote either cell death or survival (12). The activation of autophagy is frequently associated with ROS and oxidative stress. The downregulation of SOD expression in the STZ-induced DN tissues observed in the present study suggests an associated increase in oxidative stress, and this may be associated with the activation of autophagy.
The regulatory mechanism of autophagy is closely associated with the AKT signaling pathway (13). Inhibition of AKT may activate autophagy, however the opposite result has also been reported (14). Furthermore, suppression of the phosphatidylinositol-3-kinase/AKT pathway may attenuate renal fibrosis; previous findings indicated that phospho-AKT expression was upregulated in rat kidneys with chronic allograft nephropathy, and these rats presented with severe interstitial fibrosis and tubular atrophy $(15,16)$. A previous study indicated that AKT may have a bidirectional regulation role in autophagy and produce time-dependent effects, however this is also likely to be associated with the feedback regulation of AKT by Atg5 (17). In the present study, the level of autophagy was significantly increased in the renal tissue of diabetic rats, however the expression of AKT was also markedly increased. These results suggest that AKT upregulation may be associated with feedback regulation by Atg5, and other regulatory pathways of autophagy may be involved in the development of renal fibrosis associated with DN.

Similar to AKT, TGF- $\beta 1$ and NF- $\mathrm{BB}$ also have critical roles in the pathogenesis of DN $(18,19)$, and are common signaling pathways involved in autophagic regulation. TGF- $\beta$ has a central role in the pathogenesis of tissue fibrosis, and overexpression of this protein in renal tubular epithelial cells resulted in widespread peritubular fibrosis and induction of autophagy (20). Furthermore, cell culture studies indicated that TGF- $\beta$ may activate autophagy in tubular cells (21). Therefore, it seems that TGF- $\beta$ may regulate autophagy, which in turn may regulate several critical aspects of kidney fibrosis, such as tubulointerstitial fibrosis and diabetic nephropathy. Regarding NF- $\mathrm{B}$, Haar et al (22) reported that acute high-fat feeding mediates cardioprotection against ischemia-reperfusion injury, and this was associated with a $\mathrm{NF}-\kappa \mathrm{B}$-dependent increase in autophagy. The results of the present study indicate that the mechanism of renal interstitial fibrosis in diabetic rats may be associated with the activation of TGF- $\beta$ and the NF- $\kappa$ B pathways, with a subsequent increase in the level of autophagy.

Previous evidence has demonstrated that $\mathrm{H}_{2} \mathrm{~S}$ has acritical role in the pathogenesis of $\mathrm{DN}(23,24) . \mathrm{H}_{2} \mathrm{~S}$ is an endogenous signaling gas, which possesses potent anti-inflammatory, anti-oxidant and other regulatory functions (7). Together with nitric oxide and carbon monoxide, $\mathrm{H}_{2} \mathrm{~S}$ has important regulatory roles in different physiological and pathological situations. Accumulating evidence has indicated that $\mathrm{H}_{2} \mathrm{~S}$ may have an 
antifibrotic effect in the development of fibrosis in the heart, liver and kidneys (25-27). One study demonstrated a decrease in $\mathrm{H}_{2} \mathrm{~S}$-producing enzymes and subsequently a decrease in the endogenous $\mathrm{H}_{2} \mathrm{~S}$ level in plasma and tissues (28), whereas administration of exogenous $\mathrm{H}_{2} \mathrm{~S}$ was able to inhibit the development of fibrosis. The production of $\mathrm{H}_{2} \mathrm{~S}$ from L-cysteine is catalyzed primarily by two enzymes, cystathionine $\gamma$-lyase and CBS (29). The results of the present study demonstrated that CBS expression was significantly decreased in the STZ group. Compared with the control group, and the expression level of CBS protein was significantly increased in the STZ + $\mathrm{H}_{2} \mathrm{~S}$ group compared with the STZ group. In a rat model of unilateral ureteral obstruction, $\mathrm{H}_{2} \mathrm{~S}$ inhibited renal fibrosis by attenuating excessive collagen production and ECM protein expression (30). The results of the present study indicated that $\mathrm{H}_{2} \mathrm{~S}$ may attenuate mesangial matrix deposition and renal tissue fibrosis, and may inhibit excessive autophagy in the diabetic rat kidney. The protective mechanism of $\mathrm{H}_{2} \mathrm{~S}$ against diabetic nephropathy may be associated with the downregulation of autophagy.

The present study aimed to investigate whether exogenous $\mathrm{H}_{2} \mathrm{~S}$ was able to protect against the development of diabetic nephropathy. The results indicated that $\mathrm{H}_{2} \mathrm{~S}$ was able to improve proteinuria, to reduce the presence of PAS-positive zones in the renal glomerular and tubular basement membranes, and to reduce renal tissue fibrosis in STZ-induced diabetic rats. Furthermore, administration of $\mathrm{H}_{2} \mathrm{~S}$ increased the expression of SOD and decreased the production of collagen IV and expression of AKT, TGF- $\beta 1$ and NF- $\kappa \mathrm{B}$. TGF- $\beta 1$ is an essential regulator of extracellular matrix synthesis and cell proliferation, and is considered to be a marker of renal fibrogenesis, whereas collagen IV and collagen II are major extracellular matrix components (31). NF- $\kappa \mathrm{B}$ activation has been documented to be associated with renal inflammation and renal fibrogenesis (32). In neonatal rat cardiomyocytes exposed to hypoxia/reoxygenation, $\mathrm{H}_{2} \mathrm{~S}$ was able to significantly reverse the reduced cell viability and augmented cell injury, via the inhibition of autophagy (25). Jung et al (33) revealed that treatment with $\mathrm{H}_{2}$ Sattenuated unilateral ureteral obstruction-induced oxidative stress and kidney fibrosis, and activated TGF- $\beta 1$ and NF- $\kappa$ B. The antifibrotic mechanisms of $\mathrm{H}_{2} \mathrm{~S}$ may involve anti-oxidative stress and autophagy-suppressing roles, together with blockade of TGF- $\beta 1$ and NF- $\kappa \mathrm{B}$ signaling. In the present study, $\mathrm{H}_{2} \mathrm{~S}$ was observed to alleviate renal fibrogenesis and autophagy activation in diabetic kidney tissue, and this possibly occurred via regulation of SOD, AKT, TGF- $\beta 1$ and $\mathrm{NF}-\kappa \mathrm{B}$ signaling.

The results of the present study demonstrated that $\mathrm{H}_{2} \mathrm{~S}$ may improve renal tissue fibrosis of STZ-induced diabetic rats, and may reverse the dysregulation of MMPs/TIMPs and the activation of autophagy. Furthermore, $\mathrm{H}_{2} \mathrm{~S}$ intervention may inhibit oxidative stress and activation of the AKT, TGF- $\beta 1$ and $\mathrm{NF}-\kappa \mathrm{B}$ pathways, indicating that these signaling pathways may be involved in the pathogenesis of renal tissue fibrosis of diabetic rats, and may be associated with the regulation of autophagy.

In conclusion, the present study demonstrated that autophagic suppression may represent a protective mechanism of $\mathrm{H}_{2} \mathrm{~S}$ in the development of DN, by attenuating the imbalance of MMPs/TIMPs and the excessive deposition of collagen. $\mathrm{H}_{2} \mathrm{~S}$ may alleviate renal tissue fibrosis and activation of autophagy in STZ-induced diabetes, and this may occur via anti-oxidative stress mechanisms, together with blockade of AKT, TGF- $\beta 1$ and NF- $\kappa$ B signaling. Further potential mechanisms of autophagic suppression by $\mathrm{H}_{2} \mathrm{~S}$ remain poorly defined, and should be explored in the future.

\section{Acknowledgements}

This study was supported by the National Natural Science Foundation of China (grant no. 81202830).

\section{References}

1. Bentata Y, Haddiya I, Latrech H, Serraj K and Abouqal R: Progression of diabetic nephropathy, risk of end-stage renal disease and mortality in patients with type-1 diabetes. Saudi J Kidney Dis Transpl 24: 392-402, 2013.

2. Liu Y: Cellular and molecular mechanisms of renal fibrosis. Nat Rev Nephrol 7: 684-696, 2011.

3. Ding Y and Choi ME: Autophagy in diabetic nephropathy. J Endocrinol 224: R15-R30, 2015.

4. Choi AM, Ryter SW and Levine B: Autophagyin human health and disease. N Engl J Med 368: 651-662, 2013.

5. Velentzas PD, Velentzas AD, Mpakou VE, Antonelou MH, Margaritis LH, Papassideri IS and Stravopodis DJ: Detrimental effects of proteasome inhibition activity in Drosophila melanogaster: Implication of ER stress, autophagy, and apoptosis. Cell Biol Toxicol 29: 13-37, 2013.

6. Kim WY, Nam SA, Song HC, Ko JS, Park SH, Kim HL, Choi EJ, Kim YS, Kim J and Kim YK: The role of autophagy in unilateral ureteral obstruction rat model. Nephrology (Carlton) 17: 148-159, 2012.

7. Otunctemur A, Ozbek E, Dursun M, Sahin S, Besiroglu H, Ozsoy OD, Cekmen M, Somay A and Ozbay N: Protective effect of hydrogen sulfide on gentamicin-induced renal injury. Ren Fail 36: 925-931, 2014.

8. Han K, Zhou H and Pfeifer U: Inhibition and restimulation by insulin of cellular autophagy in distal tubular cells of the kidney in early diabetic rats. Kidney Blood Press Res 20: 258-263, 1997.

9. Li L, Zepeda-Orozco D, Black R and Lin F: Autophagy is a component of epithelial cell fate in obstructive uropathy. Am J Pathol 176: 1767-1778, 2010.

10. Ding Y and Choi ME: Regulation of autophagy by TGF- $\beta$ : Emerging role in kidney fibrosis. Semin Nephrol 34: 62-71, 2014.

11. Forbes MS, Thornhill BA, Minor JJ, Gordon KA, Galarreta CI and Chevalier RL: Fight-or-flight: Murine unilateral ureteral obstruction causes extensive proximal tubular degeneration, collecting duct dilatation, and minimal fibrosis. Am J Physiol Renal Physiol 303: F120-F129, 2012.

12. Lee HB, Yu MR, Yang Y, Jiang Z and Ha H: Reactive oxygen species-regulated signaling pathways in diabetic nephropathy. J Am Soc Nephro 14 (8 Suppl 3): S241-S245, 2003.

13. Cuyàs E, Corominas-Faja B, Joven J and Menendez JA: Cell cycle regulation by the nutrient-sensing mammalian target of rapamycin (mTOR) pathway. Methods Mol Biol 1170: 113-144, 2014.

14. Heras-Sandoval D, Pérez-Rojas JM, Hernández-Damián J and Pedraza-Chaverri J: The role ofPI3K/AKT/mTOR pathway in the modulation of autophagy and the clearance of protein aggregates in neurodegeneration. Cell Signal 26: 2694-2701, 2014.

15. Yang C, Cao Y, Zhang Y, Li L, Xu M, Long Y, Rong R and Zhu T: Cyclic helix B peptide inhibits ischemia reperfusion-induced renal fibrosis via the PI3K/Akt/FoxO3a pathway. J Transl Med 13: 355, 2015.

16. Zhou LN, Wang N, Dong Y, Zhang Y, Zou H, Li Q, Shi Y, Chen L, Zhou W, Han C and Wang Y: Increased Expression of p-Akt correlates with Chronic Allograft Nephropathy in Rat Kidney Model. Cell Biochem Biophys 71: 1685-1693, 2015.

17. Hu N, Kong LS, Chen H, Li WD, Qian AM, Wang XY, Du XL, Li CL, Yu XB and Li XQ: Autophagy protein 5 enhances the function of rat EPCs and promotes EPCs homing and thrombus recanalization via activating AKT. Thromb Res 136: 642-651, 2015. 
18. Sharma $\mathrm{K}$ and Ziyadeh FN: Hyperglycemia and diabetic kidney disease. The case for transforming growth factor-beta as a key mediator. Diabetes 44: 1139-1146, 1995.

19. Fornoni A, Ijaz A, Tejada T and Lenz O: Role of inflammation in diabetic nephropathy. Curr Diabetes Rev 4: 10-17, 2008.

20. Koesters R, Kaissling B,LeHir M,Picard N, Theilig F, GebhardtR, Glick AB, Hähnel B, Hosser H, Gröne HJ and Kriz W: Tubular overexpression of transforming growth factor-betal induces autophagy and fibrosis but not mesenchymal transition of renal epithelial cells. Am J Pathol 177: 632-643, 2010.

21. Ding Y, Kim JK, Kim SI, Na HJ, Jun SY, Lee SJ and Choi ME: TGF- $\{$ beta\}1 protects against mesangial cell apoptosis via induction of autophagy. J Biol Chem 285: 37909-37919, 2010

22. Haar L, Ren X, Liu Y, Koch SE, Goines J, Tranter M, Engevik MA, Nieman M, Rubinstein J and Jones WK: Acute consumption of a high-fat diet prior to ischemia-reperfusion results in cardioprotection through NF- $\mathrm{kB}$-dependent regulation of autophagic pathways. Am J Physiol Heart Circ Physiol 307: H1705-H1713, 2014.

23. Zhou X, Feng Y, Zhan Z and Chen J: Hydrogen sulfide alleviates diabetic nephropathy in a streptozotocin-induced diabetic rat model. J Biol Chem 289: 28827-28834, 2014.

24. Aminzadeh MA and Vaziri ND: Downregulation of the renal and hepatic hydrogen sulfide (H2S)-producing enzymes and capacity in chronic kidney disease. Nephrol Dial Transplant 27: 498-504, 2012.

25. Jiang $\mathrm{H}$, Xiao J, Kang B, Zhu X, Xin N and Wang Z: $\mathrm{PI} 3 \mathrm{~K} / \mathrm{SGK} 1 / \mathrm{GSK} 3 \beta$ signaling pathway is involved in inhibition of autophagy in neonatal rat cardiomyocytes exposed to hypoxia/reoxygenation by hydrogen sulfide. Exp Cell Res 345: 134-140, 2016.
26. Zhao DA, Liu J, Huang Q and Han ZM: Change in plasma $\mathrm{H} 2 \mathrm{~S}$ level and therapeutic effect of $\mathrm{H} 2 \mathrm{~S}$ supplementation in tubulointerstitial fibrosis among rats with unilateral ureteral obstruction. Zhongguo Dang Dai Er Ke Za Zhi 15: 903-908, 2013.

27. Cheng P, Wang F, Chen K, Shen M, Dai W, Xu L, Zhang Y, Wang C, Li J, Yang J, et al: Hydrogen sulfide ameliorates ischemia/reperfusion-induced hepatitis by inhibiting apoptosis and autophagy pathways. Mediators Inflamm 2014: 935251, 2014.

28. Kimura H: Physiological role of hydrogen sulfide and polysulfide in the central nervous system. Neurochem Int 63: 492-497, 2013.

29. Szabó C: Hydrogen sulphide and its therapeutic potential. Nat Rev Drug Discov 6: 917-935, 2007.

30. Kundu S, Pushpakumar SB, Tyagi A, Coley D and Sen U: Hydrogen sulfide deficiency and diabetic renal remodeling: Role of matrix metalloproteinase-9. Am J Physiol Endocrinol Metab 304: E1365-E1378, 2013.

31. Santibañez JF, Quintanilla M and Bernabeu C: TGF- $\beta /$ TGF- $\beta$ receptor system and its role in physiological and pathological conditions. Clin Sci (Lond) 121: 233-251, 2011.

32. Yoon JJ, Lee YJ, Lee SM, Kang DG and Lee HS: Oryeongsan suppressed high glucose-induced mesangial fibrosis. BMC Complement Altern Med 15: 30, 2015.

33. Jung KJ, Jang HS, Kim JI, Han SJ, Park JW and Park KM: Involvement of hydrogen sulfide and homocysteine transsulfuration pathway in the progression of kidney fibrosis after ureteral obstruction. Biochim Biophys Acta 1832: 1989-1997, 2013. 